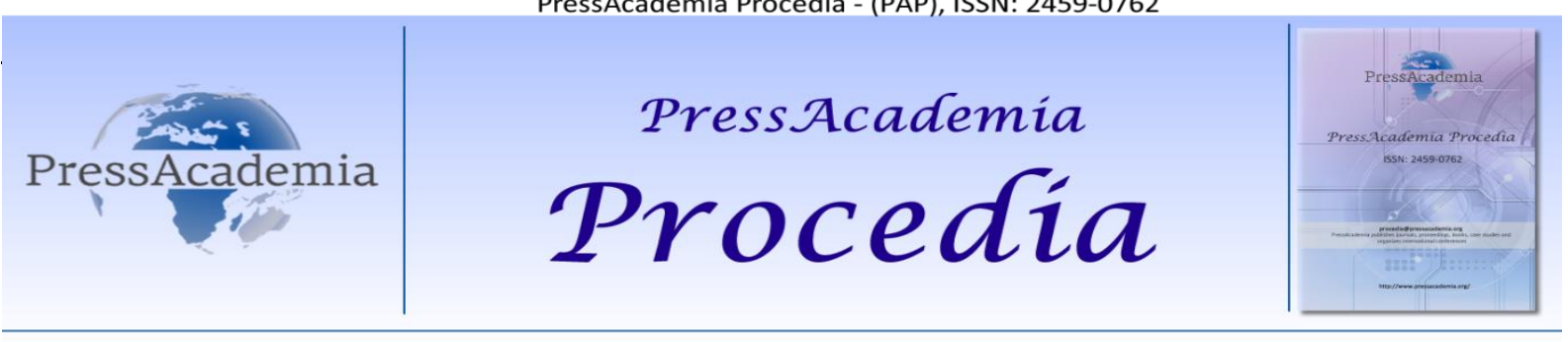

Global Business Research Congress (GBRC), May 24-25, 2017, Istanbul, Turkey.

\title{
THE INTERNATIONALIZATION PROCESS OF EMERGING MARKETS MULTINATIONAL COMPANIES (EMNC): A THEORETICAL AND CONCEPTUAL EXAMINATION ON TURKEY
}

DOI: 10.17261/Pressacademia.2017.391

PAP-GBRC-V.3-2017(6)-p.48-57

\section{Esin Can ${ }^{1}$, Nilay Utlu ${ }^{2}$}

${ }^{1} Y ı l d ı z$ Teknik Üniversitesi, Barboros Bulvarı 34349 Yıldız, İstanbul, Turkiye. eesincan@gmail.com

${ }^{2}$ Yıldız Teknik Üniversitesi, Barboros Bulvarı 34349 Yıldız, İstanbul, Türkiye. nilayutlu@gmail.com

\section{To cite this document}

Can, E. and N. Utlu, (2017). The internationalization process of emerging market multinational companies (EMNC): a theoretical and conceptual examination on Turkey. PressAcademia Procedia (PAP), V.3, p.48-57.

Permemant link to this document: http://doi.org/10.17261/Pressacademia.2017.391

Copyright: Published by PressAcademia and limited licenced re-use rights only.

\begin{abstract}
Today, the efforts and achievements of the emerging economies towards becoming multinational are paying attention to the academic and international business world. Until today, the internationalization process of developed countries companies are examined, nowadays a reversal point of view has developed and the internationalization process of emerging market multinational companies (EMNC) have begun to be studied heavily. The aim of this study is to examine the internationalization processes of EMNC by presenting current model, by making proposals to companies that want to be multinational. Starting from this aim, the internationalization processes theories of EMNC have been examined; the statistical data of international organizations are given by using documentary research method accepted as a quantitative research method and Turkish Multinational Companies are analyzed. When these theories and our multinational companies are examined, it has been found that Turkey is supported in the framework of internationalization process, Uppsala, Network, Eclectic Paradigm theories.
\end{abstract}

Keywords: Emerging countries, multinational companies, emerging markets multinational companies, internationalization process, Turkish multinational companies.

JEL Codes: F21, F23, M10.

\section{GELIŞMEKTE OLAN ÜLKE ÇOKULUSLU işLETMELERIN ULUSLARARASILAŞMA SÜRECi: TÜRKiYE ÜZERINDEN TEORIK VE KAVRAMSAL BIR INCELEME}

\section{ÖZET}

Günümüzde, gelişmekte olan ülkelerde doğan işletmelerin çokuluslu olma yolunda gösterdiği gayret ve başarı akademik ve uluslararası iş dünyasının dikkatini çekmektedir. Bugüne kadar literatürde gelişmiş ülkelerin uluslararasılaşma süreçleri üzerine yapılan çalışmalar yoğunluk gösterirken, günümüzde tersine bir bakış açısı gelişerek geçiş ekonomisine sahip ülkeler ve uluslararasılaşma süreçleri ağırlıklı olarak incelenmeye başlanmıştır. Bu çalışmanın amacı; gelişmekte olan ülkeler arasında sayılan, Türkiye'nin büyümesinde, uluslararası rekabetini arttırmasında ve ekonomik kalkınmasında önemli etkileri olan, çokuluslu işletmelerin, uluslararasılaşma süreçlerini veriler üzerinden kavramsal çerçevede inceleyerek, durum tespiti yapmak ve mevcut modeli ortaya koyarak, çokuluslu olmak isteyen, bu konuda fırsatlar yaratmaya çalışan işletmelere önerilerde bulunmaktır. Tanımlanan amaçtan hareketle, bu çalışmada, gelişmekte olan ülke çokuluslu işletmelerin uluslararasılaşma teorileri incelenmiş ve nicel araştırma yöntemi kabul edilen belgesel araştırma yöntemi kullanılarak uluslararası kuruluşlara ait istatistiki veriler ile Türk Çokuluslu işletmelerin analizine yer verilmiştir. Söz konusu teoriler ve çokuluslu şirketlerimiz incelendiğinde, Türkiye'nin uluslararasılaşma süreci, Uppsala, Şebeke Ağ, Eklektik Paradigma teorileri çerçevesinde desteklendiği bulgulanmıştır.

Anahtar Kelimeler: Gelişmekte Olan Ülkeler, Çokuluslu işletmeler, Gelişmekte Olan Ülke Çokuluslu İşletmeleri, Uluslararasılaşma Süreci, Türk Çokuluslu İşletmeler.

JEL Kodları: F21, F23, M10 


\section{Giriş}

Gelişmekte olan ülke piyasaları kavramı ilk kez Dünya Bankası Grubu'nun Uluslararası Finans Kurumu (WBG-IFC) tarafından 1981'de gelişen hisse senedi piyasalarını tanımlamak için kullanılmıştır. (Aybar \& Thirunavukkarasu, 2005, s. 21) Gelişmekte olan ülkeler, düşük veya orta-yüksek gelire sahip, serbest piyasa mekanizmalarını destekleyen ekonomik politikaları daha geniş alanda uygulayan ve endüstriyel ekonomiler tarafından elde edilene göre daha yüksek büyüme hızını gösteren piyasalar olarak değerlendirilir.(Hoskisson, Eden, Lau, \& Wright, 2000, s. 249) Fiziksel, sosyo-politik ve ekonomik özellikler aşısından henüz gelişme gösterememiş ülkeler, gelişmekte olan ülke statüsünde yer alır. Ayrıca ülkelerin gelişmişlik seviyeleri hakkında Dünya Bankası ve IMF, ülkelerin kişi başına düşen Gayri Safi Milli Hasıla'sına (GSMH) göre bir sıralama yapar. GSMH, ulusal kaynaklar tarafından bir yıl boyunca üretilen mal veya hizmet değerlerini gösterir. Buna göre ülkeler, GSMH'sı 545 dolardan az ise gelişmemiş; 545 ile 5999 dolar aralığında ise gelişmekte olan; 5999 dolar üzeri ise gelişmiş ülkeler sınıflamasında yer alır. (Daniels \& Radebough, 1994, s. 250-252) Sonuçta gelişmekte olan ülkelerde doğan işletmelerin, ülkelerindeki ekonomik ve politik istikrarsızlığa rağmen, çokuluslu nitelik kazanması, dikkat çekici olarak değerlendirilmektedir. Öyle ki, UNCTAD Dünya Yatırım Raporu'nda (2016), yurtdışına en çok yatırım yapan ilk 20 ekonomi içinde 6 adet gelişmekte olan ülke yer aldığını bildirilmiştir. Bunlar sırasıyla, Çin, Hong-Kong, Singapur, Kore Cumhuriyeti, Rusya Federasyonu, Şili'dir. Gelişmekte olan ülkeler arasında sayılan Türkiye'nin de stratejik planlarında uluslararasılaşma ve çokulusluluk yer aldığından, bu konu büyük önem taşımaktadır.

\section{LITERATüR INCELEMESI}

1980'li yılların başında sermaye hareketlerinin serbestleşip küresel ekonominin ivme kazanması, piyasa ekonomisinin gelişmesine, uluslararası üretimin ve doğrudan yabancı yatırımların artmasına neden olmuştur. Bu hareketlilik geliş̧mekte olan ülkelerin ihtiyacı olan sermayeyi doğrudan yabancı yatırımlar yoluyla karşılamalarına fırsat vermiştir. Dolayısıyla, küresel ekonomi içinde bulunan birçok işletmenin farkı ülkelere yatırım yapması "Çokuluslu işletmeler" kavramını ortaya çıkarmıştır. (Kaymakçı, 2013, s. 226)

ÇUi'ler, iki veya daha fazla ülkede mülkiyeti kısmen veya tamamen kendisine ait, kendi işletme stratejilerini tüm bağlı kuruluşlarında ve şubelerinde uygulayarak üretim ve pazarlama faaliyetlerini yürüten işletmelerdir. (Can, 2012, s. 9) ÇUi'ler, doğrudan yabancı yatırımlarla (foreign direct investment) ilgilenen, birden fazla ülkede gelir getiren aktif değerlere sahip olan veya bunları kontrol eden dolayısıyla ana ülke dışında mal ve hizmet üreten işletmelerdir. (Dunning \& Lundan, 2008, s. 3) Ancak bir işletmenin sadece yurtdışına ticaret veya yabancı firmalara aracı olarak hizmet yapması onun çUi olduğu anlamına gelmez. Bir işletmenin çokulusluluk derecesini değerlendirmenin birçok yolu vardır. Eğer bir işletme;

- Yabancı ülkelerde birçok yabancı bağlı ortaklık veya iştiraklere sahipse,

- Dünya çapında birçok farklı ülkede faaliyet gösteriyorsa,

- Toplam varlık, gelir ve karlarının yüksekliği, işletmenin yaptığı yurtdışı faaliyetlerden gelen varlık, gelir ve kar oranlarıyla ilgiliyse,

- Çalışanları, paydaşları, sahipleri ve yöneticileri farklı birçok ülkelerdense,

- Sadece satış ofislerinde değil, yurtdışı faaliyetlerinde üretim, araştırma ve geliştirme yönünden çok daha hırslıysa, söz konusu işletmenin çokulusluluk derecesinin arttığı söylenebilir. (Dunning \& Lundan, 2008, s. 3)

ÇUi'ler, merkez ve yavru işletmelerden oluşan bir bütündür. Yukarıda sayılan özelliklere göre; ÇUi'ler, merkez işletme dışında, birden çok ülkede mülkiyeti tamamen veya kısmen kendisine ait yavru işletmelerinde kendi işletme stratejileri olan üretim ve pazarlama faaliyetlerini yürüten dolayısıyla birden fazla ülkeden aktif getiri kazanan işletmeler olarak tanımlanır.

ÇUi'lerin literatürde geçen tanımlarından bahsettikten sonra, gelişmekte olan ülke çokuluslu işletmelerin (EMNC) uluslararasılaşma sürecini daha iyi anlayabilmek için gelişmekte olan ülke çokuluslu işletme teorilerini ele alacağız. Ana ülkesi gelişmekte olan ülke olan işletmelerin çokuluslu işletme olma yolunda nasıl bir süreç izlediği bu çalışmada teoriler çerçevesinde incelenecektir.

\subsection{Gelişmekte Olan Ülke Çokuluslu İ̧̧letme Teorileri}

Gelişmekte olan ülke çokuluslu işletmelerin uluslararasılaşma süreçlerini değerlendirmek için çeşitli teoriler öne sürülmüştür. Bu teoriler, çokuluslu işletmelerin yurtdışı yatırımlarının başlatılma zamanından, pazar seçimi ve giriş şekillerinin nasıl bir süreçte ilerlediğinin çerçevesini sunar. Gelişmekte olan ülke çokuluslu işletmelerin teori başlıkları aşağıdaki Şekil I-1'de gösterilmiştir. (Sakr \& Jordaan, 2016, s. 5-14) 
Şekil 1: Gelişmekte Olan Ülke Çokuluslu İşletmelerin Teorileri (Sakr \& Jordaan, 2016, s. 5-14)

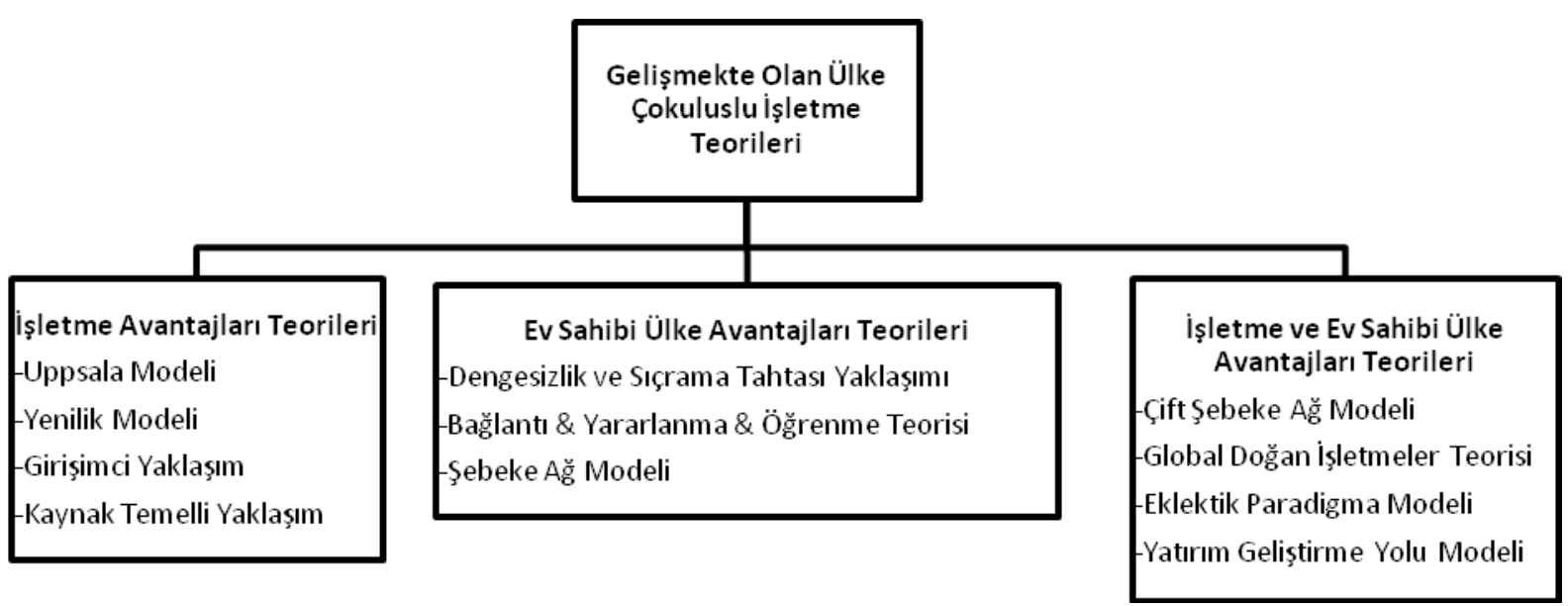

Şekil 1'de de görüldügü gibi, gelişmekte olan ülke çokuluslu işletmelerin teori başlıkları üç kategoride alt başlıklar halinde incelenmektedir. Birinci kategori, çokulusluluk sürecinde rekabet avantajına odaklanan teorilerde yer alan uppsala modeli, yenilik modeli, girişimci yaklaşım, kaynak temelli yaklaşım; ikinci kategori, ev sahipliği yapan ülkelerdeki avantajlara odaklanan teorilerde yer alan dengesizlik ve sıçrama tahtası yaklaşımı, bağlantı\& yararlanma\& öğrenme teorisi, şebeke ağ modeli; üçüncü kategori ise, hem işletme hem de ev sahipliği yapan ülke açısından var olan avantajlara odaklanan teorilerde yer alan çift şebeke ağ modeli, global doğan işletmeler teorisi, eklektik paradigma modeli, yatırım geliştirme yolu modelidir.

\subsection{1. İ̧̧letme Avantajları Teorileri}

İşletme avantajları teorileri, gelişmekte olan ülke çokuluslu işletmelerin yurtdışına açılırken hedeflenen pazarda faaliyet gösteren rakip işletmelerden üstün sahip oldukları rekabet avantajları konusuna odaklanır. Söz konusu rekabet avantajı işletmeye özgü olan mülkiyet ve mülkiyeti olmayan avantajlar olarak ikiye ayrılır. Mülkiyet avantajlarında, işletmenin sahip olduğu patent ve markadan; mülkiyeti olmayan avantajlarında ise, know-how üretim süreci, yönetim yapıları, iş ilişkisi ağlarından bahsedilir. (Andreff \& Balcet, 2013, s. 12) Rekabet avantajına sahip olmanın bu çeşitliliği, gelişmekte olan ülke çokuluslu işletmelerin uluslararasılaşma süreçlerini açıklamaya yardımcı teorileri geliştirmiştir. Bu teoriler, Uppsala Modeli, Yenilik Modeli, Girişimci Yaklaşım, Kaynak Temelli Yaklaşımdır. (Sakr \& Jordaan, 2016, s. 6)

Uppsala Modeli, Johanson ve Weidersheim-Paul (1975), Johanson ve Vahlne (1977) tarafından geliştirilen işletmelerin dış piyasalara girişinde birbirini takip eden dört aşamalı sürecinden bahseder. (Çavuşgil \& Knight, 1996, s. 13) (Andersen, 1993, s. 210)

1. Aşama: Düzenli olmayan ihracat faaliyetleri

2. Aşama: Bağımsız temsilci aracılığıyla ihracat

3. Aşama: Dış ülkelerde açılan satış bürolarıyla yapılan ihracat

4. Aşama: Yurt dışı üretim/imalat

Şekil 2: Uppsala Modelinde Uluslararasılaşma Süreci (Johanson \& Vahlne, 1977, s. 26)

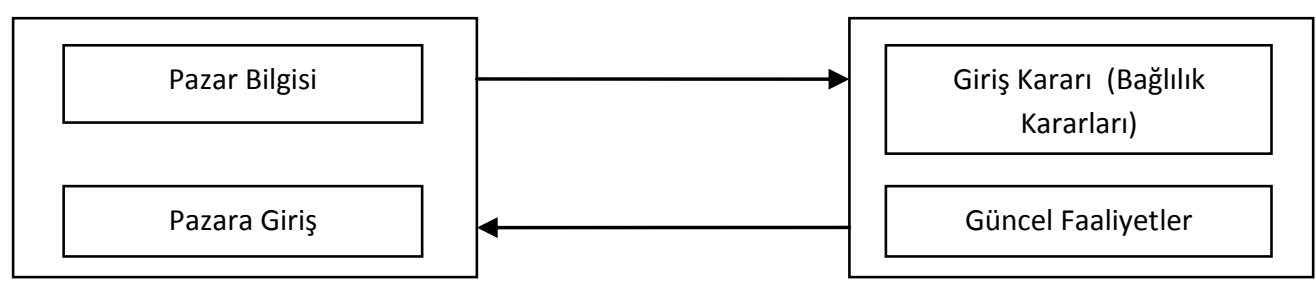


İşletmeler dış pazarlara girerken uluslararası işletmecilik bilgisinin yanı sıra hedef pazar bilgisine de sahip olmalıdır. Pazar bilgisi de yaşanan tecrübelerle elde edilir. Kazanılan bilgiler işletme pazarını genişletebileceği gibi, bir pazardan diğer pazara da taşınabilir. Uppsala modelinde, uluslararasılaşma sürecinde elde edilen tecrübeye dayalı bilgi, geleneksel uluslararası dış pazarlara giriş bilgisinden daha kıymetlidir. (Erkutlu \& Eryiğit, 2001, s. 157)

Uppsala modeline göre, işletmeler dış pazarları tecrübeleriyle öğrenir. İşletmeler, bilgi sahibi olmadığı dış pazarlara kaynak aktarmadan önce, yeterli tecrübe kazanmak ister. Bu da uluslararasılaşma sürecinin uzamasına neden olur. Johanson ve Vahlne'ne göre (1977), bu sürecin yavaş ve aşamalı olması, işletmelerin çevreye ve değişen yeni koşullara uyum göstermeye çalışmasından kaynaklanır. (Çavuşgil \& Knight, 1996, s. 13)

Johanson ve Vahlne, Uppsala modelini açıklarken "psikolojik yakınlık faktörü”nden de bahsetmiştir. Buna göre işletmeler uluslararasılaşma sürecinde kültür, dil, gelenek ve politik sistemler olarak kendilerine yakın olan yerleri tercih eder. (Johanson \& Vahlne, 1977, s. 24) Dolayısıyla, işletmeler en iyi bildikleri pazarı, hedef pazar olarak seçer, kaynaklarını hedef pazara aktarır, bu da dış pazara bağlılıklarını arttırır. Upssala modelinde, işletmelerin uluslararasılaşması birbirini takip eden aşamalarla sistematik şekilde gelişen bir süreç olarak karşımıza çıkar.

Yenilik Modeli, işletmelerin çokulusluluk sürecini açıklayan bir diğer model ise yenilik modelidir. Yenilik modeli de tıpkı Uppsala modeli gibi işletmelerin uluslararasılaşma sürecinin aşamalı ve yavaş olduğunu ve pazar seçiminde psikolojik yakınlık faktörünün etkili olduğunu söyler. Ancak Uppsala modelinden farklı olarak uluslararasılaşma süreci yönetimde bir yenilik kararı olarak görülür. (Çavuşgil \& Knight, 1996, s. 14)

Girişimci Yaklaşım, uluslararasılaşma sürecinde üst yönetimin veya girişimcinin rolünü vurgular. Uluslararasılaşma sürecinde, üst yönetim veya girişimci, küresel odaklı stratejiler benimseyerek, uluslararası iş topluluklarıyla ağlar kurarak, keşfederek, dış yatırım fırsatlarını görerek, dış iştirakleri yöneterek etkili bir rol oynayabilir. (Sakr \& Jordaan, 2016, s. 7)

Kaynak Temelli Yaklaşım, işletmelerin sürdürülebilir rekabet avantajı sağlayacak stratejik kaynaklara sahip olması yurtdışı yatırım yapmaya meyilli olduğunu söyler. Bunlar, değerli, nadir, taklit edilemez, ikame edilemez stratejik kaynaklardır. (Barney, 1991, s. 101-105)

\subsubsection{Ev Sahibi Ülke Avantajları Teorileri}

Gelişmekte olan ülke çokuluslu işletmeleri genellikle ana ülkelerinde sahip olabilecekleri rekabet avantajlarından yoksun olduğundan uluslararasılaşma sürecini başlatmak için ev sahibi ülkede rekabet avantajı sağlayacak arayışlara girer. Ev sahibi ülkelerde bulunan avantajlar, gelişmekte olan çokuluslu işletmeler için uluslararasılaşma sürecini başlatmada tetikleyici olur. (Andreff \& Balcet, 2013, s. 11) Bu görüşü benimseyen ev sahibi ülke avantajları başlığında üç teori vardır. Bunlar, Dengesizlik ve Sıçrama Tahtası Yaklaşımı, Bağlantı \& Yararlanma \& Öğrenme Teorisi, Şebeke Ağ Modeli. (Sakr \& Jordaan, 2016, s. 9)

Dengesizlik ve sıçrama tahtası yaklaşımı, gelişmekte olan ülke çokuluslu işletmeler, uluslararasılaşma sürecini başlatırken yapacağı doğrudan yabancı yatırım için ev sahibi ülkeleri, tramplen ya da sıçrama tahtası olarak düşündüğünü söyler. (Sakr \& Jordaan, 2016, s. 9)

Bağlantı, yararlanma, öğrenme teorisi, Mathew (2006) tarafından gelişmekte olan ülke çokuluslu işletmelerin uluslararasılaşma sürecini tanımlamak için geliştirilmiştir. Bu teoride, gelişmekte olan ülke çokuluslu işletmeler, uluslararasılaşma sürecinin hızlı olmasından "ejderha işletmeler" olarak tanımlanır. (Mathews, 2006, s. 5) Ejderha işletmelerin üç özelliği vardır; bağlantı, yararlanma ve öğrenme. (Mathews, 2006, s. 18)

Şebeke ağ modeli, işletmelerin uluslararasılaşmasını ağırlıklı olarak içinde bulunduğu şebeke ağına bağıı olduğunu söyler. Bir şebeke ağı, aynı işi yapan işletmelerin birbirlerine bağlı oluşturdukları örgütler arası ilişkiler kümesidir. Bu tür ilişkilerin veya şebeke ağın oluşturulması çaba gerektiren ve zaman alıcıdır. (Sakr \& Jordaan, 2016, s. 10)

İşletmelerin üst yöneticilerinin ya da çalışanlarının, müşteri, tedarikçi, dağıtıcı, rakip, banka, aile, arkadaş, herhangi bir kurum ya da kuruluşla olan ilişkileri uluslararasılaşmasına olanak sağlayan faktörler olarak görülür. İ̧̧letmelerin uluslararasılaşmasında örgütsel sınırı formel ve informel ilişkilerle belirler. (Coviello \& Martin, 1999, s. 44) Şebeke ağı modelinde bahsedilen ilişkiler ağı, uluslararasılaşmada işletmeleri motive eder ve onlara destek verir. (Zain \& Ng, 2006, s. 186)

Şebeke ağ modeli ile bağlantı, yararlanma, öğrenme teorisine göre iş dünyasında şebeke ağları kurmak çok önemlidir. Her iki yaklaşım da şebeke ağlarının, işletmelerin kaynak temin etmesinde yardımcı olacağını söyler. Ancak Bağlantı, Yararlanma, Öğrenme teorisinde işletmelerin çokuluslu olması şebeke ağ modeline göre daha erken olması beklenir. Şebeke ağ modelinde işletmelerin çokuluslu olması birikimli ve zaman alıcı bir süreci kapsar. (Sakr \& Jordaan, 2016, s. 10) 


\subsection{3. İ̧letme ve Ev Sahibi Ülke Avantajları Teorileri}

Iş̧letme ve ev sahibi ülke avantajları teorileri, yukarıda sayılan teorilerden daha tutarlı ve kapsamlı olarak kabul edilir. Çünkü hem işletmenin sahip olduğu kaynakları kullanma, hem de ev sahibi ülkedeki kaynaklara erişim imkanı açısından avantajlardan bahseder. İşletme ve ev sahibi ülke avantajları başlığında dört teori vardır. Bunlar, Çift Şebeke Ağ Modeli, Küresel Doğan İşletmeler Teorisi, Eklektik Paradigma Modeli, Yatırım Geliştirme Yolu Modelidir. (Sakr \& Jordaan, 2016, s. 1014)

Çift şebeke ağ modeli, gelişmekte olan ülke çokuluslu işletmelerin uluslararasılaşma sürecindeki bağlantıları iki kategoride inceler: iç ve dış şebeke ağları. İç şebeke ağ, çokuluslu işletmelerin iç birimleri (bağlı kuruluşlar ve genel merkez) arasında karşılıklı bağımlılık ilişkileridir. İç şebeke ağ, çokuluslu işletme içindeki bilgi ve teknoloji gibi kaynakların dolaşımından sorumludur. iç şebeke ağında, merkez işletme, sahip olduğu kendi kaynakları dışında, ek kaynak ve bilgilere erişmek için bağlı diğer kurum ve kuruluşlarla şebeke ağları oluşturur. Dış şebeke ağı ise, yalnızca işletmeye bağlı kurum ve kuruluşlarla değil, işletmenin dışında kalan (üniversiteler, araştırma ve düşünce kuruluşları gibi) kurum ve kuruluşlardan oluşturulan şebeke ağını kapsar. İ̧̧ ve dış şebeke ağı birbirinden ayrı düşünülemez. İç şebeke ağının genişlemesiyle dış şebeke ağı da genişler. (Zanfei, 2007, s. 19)

Küresel doğan işletmeler teorisi, İngilizcede "Born Global", "International New Venture", "Global Start-ups", "Infant Multinational Corporations", "Leapfrogging Firms" olarak çeşitli isimlerle geçer ve bu teoride işletmeler, uluslararası pazarlara geleneksel teorilerde bahsedilen aşamalardan geçmeden kısa bir sürede girer. (Rasmussen \& Madsen, 2002, s. 13)

Eklektik Paradigma, İngilizcede "OLI Paradigm" olarak da bilinir ve Dunning tarafından önceki teorilerin derlemesinden oluşturulmuştur. Bu yüzden teori yerine paradigma kavramı kullanılır. Eklektik paradigmaya göre, işletmeler sahip oldukları üç avantaj şartına göre uluslararası faaliyetler yapmaya karar verir. Bunlar: (Dunning, 1988, s. 2-5)

1. Sahiplik (O-Ownership) Avantajı: Ev sahibi ülkelerdeki işletmelere göre, işletmelerin kendilerine özgü birtakım özelliklere sahip olması. Burada, yönetim becerisi, yenilik kapasitesi, tanınmıs markalara sahip olma, önemli iş süreçlerine sahip olma gibi avantajlardan bahsedilir.

2. Konum (L-Location) Avantajı: İşletmeye göre dış pazarların yerel pazarlardan daha iyi olması. Burada, pazarın büyüklüğü, ucuz üretim faktörlerinin mevcudiyeti gibi avantajlardan bahsedilir.

3. İçselleştirme (I-Internalisation) Avantajı: İşletmenin sahiplik avantajları nedeniyle elinde bulunan varlıklarını, başka bir işletmeye lisans verme, franchise anlaşması yapma yerine kendi kuracağı yavru şirket (içselleştirmesi) ile dış pazarda faaliyet göstermenin daha karlı olmasıdır. Burada, diğer işletmelerle görüşme ve araştırma maliyetlerinden kaçınma, yapılan anlaşmaların bozulması ihtimalinde doğacak maliyetlerden kaçınma, tedarikçilerin kontrolü gibi avantajlardan bahsedilir.

Eklektik paradigmaya göre, işletme ve ev sahibi ülke açısından sahip olunan avantajlara bütüncül bir bakış açısı getiren "OLI" şartlarının gerçekleşmesiyle, işletmeler uluslararasılaşma sürecine başlayacaktır.

Yatırım geliştirme yolu modeli, eklektik paradigmaya dinamik bir yapı kazandırılmış halidir. Eklektik paradigma, işletmelerin uluslararasılaşma sürecine hangi koşullarda başladığını ele alırken, yatırım geliştirme yolu modeli de bu sürecin nasıl ilerlediğini ele alır. (Buckley \& Castro, 1998, s. 1)

\section{VERI VE YÖNTEM}

Bu çalışmada, nicel araştırma yöntemi kabul edilen belgesel araştırma yöntemi kullanılarak, gelişmekte olan ülkeler arasında sayılan Türkiye'nin çokuluslu işletmelerin uluslararasılaşma süreçleri, uluslararası kuruluşlara ait istatistiki veriler çerçevesinde incelenmiştir.

\section{BULGULAR VE TARTIŞMA}

\subsection{Türk Çokuluslu İşletmeler}

Türkiye'nin uluslararasılaşma süreci, Türk çokuluslu işletmelerin yaptıkları doğrudan yabancı yatırımlar çerçevesinde incelenir. Doğrudan yabancı yatırımlar, bir işletmenin kendi üretim tesislerini yabancı ülkede kurması (fully owned subsidiary veya greenfield investment); ya da kurulu bir işletmeyle birleşmesi veya onu satın alması (merger veya acquisition) yoluyla iki türlü gerçekleşen dış pazara giriş stratejilerindendir. (Can, 2012, s. 125) Bu tanımdan da çıkarılacağı gibi, DYY ile ÇUi kavramı birbiriyle paralel gider. Bir işletmenin ÇUi olabilmesi için ana ülkesi dışında birden fazla ülkede DYY gerçekleştirmiş olması gerekir. Dolayısıyla DYY, uluslararasılaşmanın en üst düzeyidir. Günümüzde dünyanın çeşitli bölgelerinde bulunan DYY'leri ile faaliyetlerini sürdüren 29 tane Türk ÇUi bulunmaktadır. (DEiK, 2014, s. 3) 
Tablo 1: Yabancı Varlıklarına Göre En Büyük 29 Finansal Olmayan Türk Çokuluslu İşletme (KHÜ - DEiK - VCC Türk Çokuluslu İşletmeleri Araştırması, 2014)

\begin{tabular}{|c|c|c|c|}
\hline Sira & İşletme Adı & Sektör & Yabancı Varlıklar \\
\hline 1 & TPAO & Petrol ve doğalgaz & 4,872 \\
\hline 2 & Anadolu Grubu & Holding & 4,443 \\
\hline 3 & Enka İnşaat & Altyapı ve Gayrimenkul & 3,779 \\
\hline 4 & Koç Holding & Holding & 3,333 \\
\hline 5 & Doğuş Grubu & Holding & 3,104 \\
\hline 6 & Yıldırım Holding & Holding & 1,867 \\
\hline 7 & Şişecam A.Ş. & Cam & 1,368 \\
\hline 8 & Yıldız Holding & Gıda ve İçecek & 1,277 \\
\hline 9 & Tekfen Holding & Holding & 1,250 \\
\hline 10 & Zorlu Enerji Grubu & Enerji & 1,120 \\
\hline 11 & TAV Holding & Holding & 1,081 \\
\hline 12 & Turkcell & İletişim & 1,057 \\
\hline 13 & Borusan Holding & Holding & 973 \\
\hline 14 & Sabancı Holding & Holding & 828 \\
\hline 15 & Çalık Holding & Holding & 816 \\
\hline 16 & Hayat Holding & Holding & 780 \\
\hline 17 & Gübretaş & Gübre & 686 \\
\hline 18 & Alarko Grubu & Holding & 651 \\
\hline 19 & Orhan Holding & Holding & 534 \\
\hline 20 & Doğan Holding & Holding & 486 \\
\hline 21 & Türk Telekom & Illetişim & 444 \\
\hline 22 & Türk Havayolları & Havayolu & 400 \\
\hline 23 & Ekol Lojistik & Lojistik & 375 \\
\hline 24 & Eczacıbaşı Holding & Holding & 371 \\
\hline 25 & Kürüm Holding & Demir Çelik & 281 \\
\hline 26 & Teklas & Otomotiv & 175 \\
\hline 27 & Çelebi Holding & Holding & 167 \\
\hline 28 & Eroğlu Holding & Tekstil & 148 \\
\hline 29 & Evyap & Tüketici Ürünleri & 98 \\
\hline & & Toplam & 36,766 \\
\hline
\end{tabular}

Tablo 1'de, Kadir Has Üniversitesi, Dış Ekonomik İlişkiler Kurulu (DEiK) ve ABD merkezli Columbia Üniversitesi işbirliğiyle hazırlanan "Çokuluslu Türk İşletmeleri"”" raporunda, yabancı varlıklarına göre en büyük finansal olmayan 29 Türk çokuluslu işletme bulunmaktadır. Raporda adı geçen çUi'lerin yurtdışında 426 iştirakleri bulunmaktadır. İştirak sayısı açısından, 14 ülkede 64 iştirak ile en önde Doğan Holding gelirken, ardından 18 ülkede 50 iştirak ile Doğuş Holding ve 9 ülkede 42 iştirak ile Enka inşaat gelmektedir. (DEIK, 2014, s. 4)

\subsection{Türk Çokuluslu İ̧̧letmelerin Uluslarasılaşma Süreci}

Gelişmiş ülkelerden çıkan DYY'ler genellikle ilk sıralarda yer alsalar da gelişmekte olan ülke olan Türkiye'den çıkan DYY'lerin yıllar itibariyle hız kazandığını söylemek mümkündür. 1980 sonrasında ekonomik alanda gerçekleştirdiği reformlarla DYY çıkışlarında önemli bir hız kazanmıştır. Bu dönemde liberalleşme ve özelleştirme politikalarıyla, serbest ekonomiye geçiş Türk işletmelerinin uluslararasılaşması için uygun bir ortam sağlamıştır. (Erdilek, 2008, s. 746) Ayrıca coğrafi olarak yakın olan SSCB'nin ve Balkanlar'daki komünist rejimin çöküşüyle Türk işletmelerin bu ülkelerde varlıklarını göstermelerine fırsat vermiştir. (Erdilek, 2008, s. 751)

Liberalleşme süreciyle bu dönemde Türkiye, uluslararasılaşmayı destekleyen bir eğilim göstermiştir. Türkiye, bu dönemde Türk işletmelerinin yabancı pazarlara açılmalarına teşvik edici politikalar izlemiştir. 1996 yılında Türkiye, Avrupa Birliği ile "Gümrük Birliği" anlaşması imzalamış, uluslararası sermaye serbestliğine ilk adımını atmıştır. Türkiye'nin Gümrük Birliği'ne 
üyeliği, Türk ekonomisinin uluslararasılaşma sürecine şüphesiz hız kazandırmıştır. (Özkara, Kurt, \& Karayormuk, 2008, s. 67) Ancak 2001 yılında ortaya çıkan ekonomik kriz ve tek parti hükümeti başlangıcı, Türkiye'nin DYY çıkışlarında \% 71'lik düşüşe neden olmuştur. (DEik, 2014) Türkiye'den çıkan DYY'lerin önü yasal olarak açılmış olsa da ülkede yaşanan ekonomik istikrarsızlık nedeniyle 2003 yılına kadar yatırımlar düşük seviyelerde seyretmiştir. 2001 yılında ortaya çıkan ekonomik kriz ile Türk ekonomisindeki daralma, makroekonomik değişkenlerin istikrarsızlığı, yatırım ortamına karşı duyulan güven kaybı, üretim faktörlerinin maliyetlerindeki artış, gelecek dönemlerde Türk işletmelerinin yabancı pazarlara yönelmesine yol açmıştır.

Şekil 3: 2000-2008 Yılları Arasında Türkiye'den Çıkış Yapan DYY Akımları (Milyon ABD Doları) (UNCTAD, 2016)

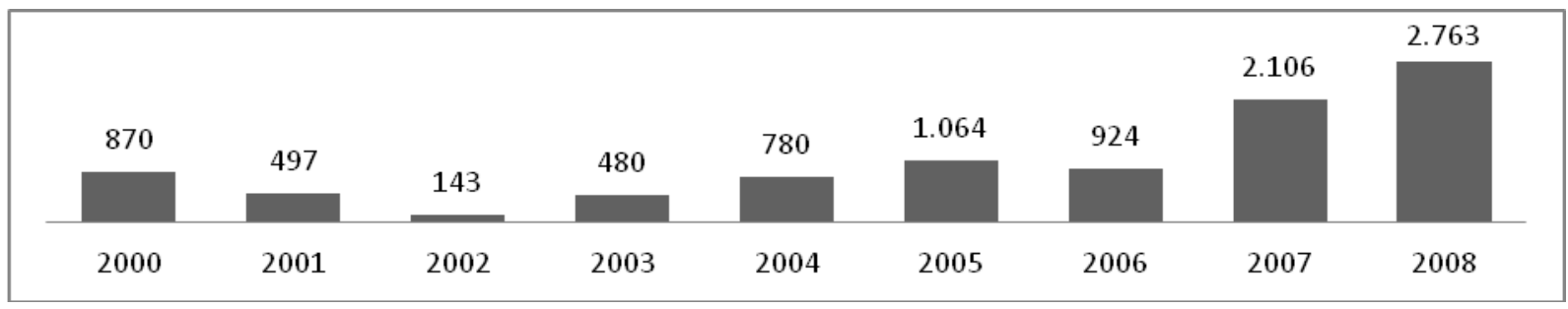

Nitekim Şekil 3'te görüldüğü gibi 2001 yılında 497 milyon ABD dolar olan sermaye ihracı, 2002 yılında 143 milyon ABD dolar, 2003 yılında 480 milyon ABD dolar olarak düşüş gösterirken, 2004 yılında 780 milyon ABD dolar, 2005 yılında 1.064 milyon ABD dolar olarak gerçekleşmiştir. Sonuçta Türkiye'den çıkan DYY'ler 2003 yılından itibaren tekrar artma eğilimi göstermiştir. 2006 yılında, Türkiye'de siyasi ve ekonomik ortamda istikrarın sağlanmasıyla, DYY çıkışlarında düşüş görülürken; 2007 ve 2008 yıllarında DYY çıkışlardaki artışın nedeni büyük çapta birleşmeler ve satın almalar olmuştur. 2007 yılında, Ülker Şirketler Topluluğu, 80 yıllık lüks çikolata ikonu Belçikalı Godiva'yı 850 milyon ABD dolara satın alarak Türk ekonomisinin en büyük satın almasını gerçekleştirmiştir. (Ntv, 2007) 2008 yılında ise, dünyada yaşanan ekonomik kriz ile işletme değerlerinin düşmesi, krizden etkilenmeyen Türk işletmelerinin satın almalarını arttırmıştır.

Şekil 4: 2009-2015 Yılları Arasında Türkiye'den Çıkış Yapan DYY Akımları (Milyon ABD Doları) (UNCTAD, 2016)

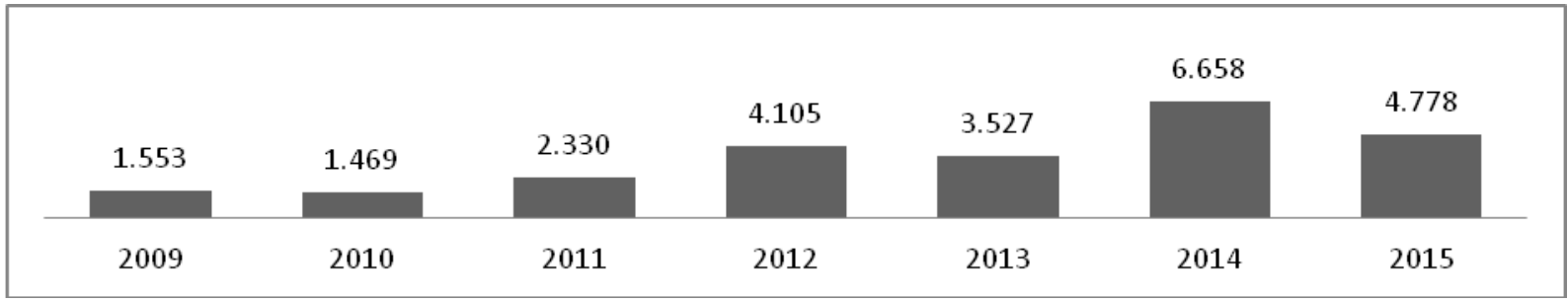

Şekil 4'te görüldügü gibi 2009 yılında Türkiye'de DYY çıkışlarında kayda değer bir düşüş yaşanmıştır. 2009 yılında 1.553 milyon ABD doları değerinde gerçekleşen sermaye ihracının nedeni, sınır ötesi birleşme ve satın alma işlemlerindeki azalmaya bağlanmaktadır. Ancak 2010 yılından 2012 yılına doğru yükselen bir seyir izleyen DYY çıkışları 2012 yılında daha önce ulaşmadığı seviyede, 4.105 milyon ABD doları değerinde gerçekleşmiştir. 2013 yılında 3.527 milyon ABD doları, 2014 yılında 6.658 milyon ABD doları, 2015 yılında ise 4.778 milyon ABD doları seviyesinde gerçekleşmiştir. 2015 yılında, Türkiye'de seçimlerin tekrarlanması, bölgesel siyasi ve güvenlik risklerin artması ve uluslararası ekonomik belirsizliklerin oluşması DYY çıkışlarında düşüşe sebep olmuştur. Sonuçta yıllar itibariyle Türkiye'nin DYY çıkış stratejisinde bütüncül bir bakışa sahip olmaması, dönemsel iniş çıkışların sebebi olarak görülebilir.

Türkiye'den çıkan DYY'lerin dünya üzerindeki bölgelere göre dağılımları, Türkiye Cumhuriyeti Merkez Bankası, İstatistik Genel Müdürlüğü başkanlığında Ödemeler Dengesi Müdürlüğü’nün yayınladığı "Uluslararası Yatırım Pozisyonu” raporunda incelenebilir. Bu raporda, Türkiye'den çıkan DYY stoklarına (belirli bir zaman noktasında ölçülen ve o an var olan büyüklüğü gösteren sermaye birikimi) bakarak, Türk işletmelerinin 2001-2014 yılları arasında en çok hangi bölgelerde yatırım gerçekleştirdiği görülür. (TCMB, 2016) 
Tablo 2: 2001-2014 Yılları Arasında Bölgelere Göre Türkiye'den Çıkan DYY Stokları (Milyon ABD Doları) (TCMB, 2016)

\begin{tabular}{|l|l|l|l|l|l|l|}
\hline & Avrupa & Afrika & Amerika & Asya & $\begin{array}{l}\text { Okyanusya ve } \\
\text { Kutup Bölgesi }\end{array}$ & TOPLAM \\
\hline $\mathbf{2 0 0 1}$ & 3.131 & 22 & 267 & 1.161 & 0 & 4.581 \\
\hline $\mathbf{2 0 0 2}$ & 4.164 & 60 & 281 & 1.342 & 0 & 5.847 \\
\hline $\mathbf{2 0 0 3}$ & 4.392 & 67 & 267 & 1.412 & 0 & 6.138 \\
\hline $\mathbf{2 0 0 4}$ & 4.702 & 72 & 278 & 2.008 & 0 & 7.060 \\
\hline $\mathbf{2 0 0 5}$ & 5.093 & 86 & 283 & 2.853 & 0 & 8.315 \\
\hline $\mathbf{2 0 0 6}$ & 5.407 & 90 & 293 & 3.076 & 0 & 8.866 \\
\hline $\mathbf{2 0 0 7}$ & 8.042 & 171 & 298 & 3.699 & 0 & 12.210 \\
\hline $\mathbf{2 0 0 8}$ & 11.210 & 381 & 1.476 & 4.778 & 1 & 17.846 \\
\hline $\mathbf{2 0 0 9}$ & 12.409 & 362 & 1.729 & 5.408 & 15 & 19.923 \\
\hline $\mathbf{2 0 1 0}$ & 12.894 & 530 & 1.942 & 5.355 & 40 & 20.761 \\
\hline $\mathbf{2 0 1 1}$ & 14.229 & 504 & 2.756 & 6.355 & 53 & 23.897 \\
\hline $\mathbf{2 0 1 2}$ & 17.300 & 412 & 2.271 & 7.286 & 244 & 27.513 \\
\hline $\mathbf{2 0 1 3}$ & 19.602 & 589 & 2.480 & 7.024 & 223 & 29.918 \\
\hline $\mathbf{2 0 1 4}$ & 20.653 & 581 & 2.845 & 9.564 & 295 & 33.938 \\
\hline
\end{tabular}

Tablo 2'de görüldüğü gibi, 2001-2014 yılları arasında, Türkiye'den çıkan DYY stok değerleri, her yıl, en çok Avrupa bölgesinde gerçekleşmiştir. Avrupa bölgesini takiben DYY stoklarının en çok bulunduğu bölgeler sırasıyla, Asya, Amerika, Afrika, Okyanusya ve Kutup Bölgesi olmuştur. Tablo II-2'de göze çarpan bir değer ise Okyanusya ve Kutup Bölgesi'ne Türkiye'nin ilk kez 2008'de yatırım yapmış olmasıdır. Şüphesiz çokuluslu işletmeler, DYY'lerin hangi bölgede olacağına dair birçok faktörü göz önünde bulundurur. Ancak tablodaki sıralamadan en basit çıkarımla, Türk çokuluslu işletmelerinin DYY bölge seçimlerinde coğrafi yakınlığın etkili olduğunu söylemek mümkündür. Ayrıca 2014 yılında DEik'in yaptığı araştırmaya göre, yapılan mülakatlar sonucu, Türk yatırımcıların kısa ve orta vadeli yurt dışı yatırımlarının \%80'inin 4 saatlik uçuş uzaklığındaki bölgelerde yoğunlaştığı görülmüştür. (DEiK, 2014)

\section{SONUC}

Gelişmekte olan ülke çokuluslu işletmeleri, gelişmekte olan ekonomilere dayanan, yurtdışına yapılan birden çok DYY'leri kontrol eden işletmelerdir. Hangi ülkelerin gelişmekte olan ülke piyasası olarak sınıflandırıldığı konusunda uluslararası kuruluşlar tarafından herhangi bir mutabakat bulunmadığından, çok sayıda gelişmekte olan ülke listelerinin bulunduğunu söylemek gerekir. Türkiye, gelişmekte olan ülkeler arasında sayıldığından çokuluslu işletmelerin uluslararasılaşma süreçleri bahsedilen teoriler çerçevesinde incelenmiştir. Bu teoriler, gelişmekte olan ülke çokuluslu işletmelerin uluslararası pazarlara giriş şekillerine, zamanlarına ve pazar seçimlerine göre sınıflandırılmıştır. Türk çokuluslu işletmelerin yurt dışına yaptıkları DYY'lerin zamanlarına, pazar seçimlerine dair bulgular elde edilmiştir.

Araştırma bulgularından hareketle araştırmada ele alınan ÇUi'lerin ihracat için genelde yakın olan ülkeleri "ilk ihracat faaliyeti” için tercih ettikleri görülmektedir. ÇUi'ler yurt dışına yapacakları DYY'lerden önce ihracat ile söz konusu pazarda bilgi sahibi olmak, tecrübe kazanmak istemektedir. Uluslararasılaşmanın yavaş ve aşamalı olması, Uppsala modelindeki uluslararasılaşma sürecini gösterir. Türk ÇUi'lerin daha çok Avrupa pazarlarında DYY gerçekleştiği görülmektedir. Böyle bir tercih, Uppsala modelindeki yakınlık kriterini ortaya koymaktadır. Ayrıca 2009-2014 yılları Türkiye'nin yurt dışına DYY stok değerleri incelendiğinde, en çok yatırımın Azerbaycan'a gerçekleştiği görülmektedir. Bu, Azerbaycan pazarı açısından düşünülecek olursa, çUi'lerin sadece fiziksel yakınlık faktörünün değil, aynı zamanda kültürel yakınlık ile iş yakınlığı gibi faktörlerin önemli olduğunu Uppsala modelindeki gibi yansıtmaktadır.

Uluslararasılaşma teorileri incelendiğinde Türk ÇUi'lerin büyük çoğunluğunun uluslararasılaşma süreçlerinde şebeke ağ modelini tercih ettiği görülmektedir. Şebeke ağ modelinde uluslararasılaşmaya olanak sağlayan faktörler arasında en büyük aktör olarak müşteriler gösterilir. Türk ÇUi'lerin de müşterileri yanı sıra üst yöneticileri, çalışanları, tedarikçileri, dağıtıcıları, rakipleri, banka, aile ve arkadaşları ile kurdukları kurdukları iyi ilişkiler tabanında uluslararasılaşmaya yön verdikleri görülmektedir. 
Eklektik paradigma, diğer uluslararasılaşma teorilerine göre dünya genelinde en doğru konumda gerçekleşecek tedarik zinciri faaliyetlerine sahip olma, kontrol etme ve en iyi şekilde kullanmayı sağlayan avantajlar sunar. Eklektik paradigmadaki gibi; Türk ÇUi'lerin de yönetim becerisi, yenilik kapasitesi, tanınmış markalara ve önemli iş süreçlerine sahiplik avantajından; dış pazarların yerel pazardan daha elverişli olduğu konum avantajından; kendi kuracağı yavru şirketin daha karlı olacağı içselleştirme avantajından faydalanarak uluslararasılaşma süreçlerine yön verdikleri gözlemlenmektedir.

\section{KAYNAKLAR}

Andersen, O. (1993). The Internalization Process of Firms: A Critical Analysis. Journal of International Business Studies, 24(2), $209-231$.

Andreff, W., \& Balcet, G. (2013). Emerging Countries' Multinational Companies Investing in Developed Countries: At Odds with the HOS Paradigm. The European Journal of Comparative Economics, 10(1), 3-26.

Aybar, B., \& Thirunavukkarasu, A. (2005). Emerging market multinationals: an analyzing of performance and risk characteristics. Journal of Asia-Pasific Business, 6(2), 5-39.

Barney, J. (1991). Firm Resources and Sustained Competitive Advantage. Journal of Management, 17(1), 99-120.

Buckley, P. J., \& Castro, F. B. (1998). The Investment Development Path: The Case of Portugal. Transnational Corporations, 7(1), 1-15.

Can, E. (2012). Uluslararası Işletmecilik . İstanbul: Beta Basım.

Coviello, N. E., \& Martin, K. A. (1999). Internationalization of Service SMEs: An Integreted Perspective From the Engineering Consultion Sector. Journal of International Marketing, 7(4), 42-66.

Çavuşgil, S. T. (1997). Measuring the Potential of Emerging Markets: An Indexing Approach. Business Horizons, 87-91.

Çavuşgil, T., \& Knight, G. A. (1996). The Born Global Firm: A Challenge to Traditional Internalization Theory. Advences in International Marketing, 8, 11-26.

Daniels, J. D., \& Radebough, L. H. (1994). International Business Environments and Operations. Canada: Addison Wesley publishing Company.

DEiK. (2014). Değerlenen Amerikan dolarına Rağmen Türk Şirketlerinin Yurtdışı Yatırımları Artmaya Devam Ediyor.

DEIK. (2014). Dünyada ve Türkiye'de Yurtdışı Doğrudan Yatırımlar. İstanbul: Yurtdışı Yatırımlar İş Konseyi.

Dunning, J. H. (1988). The Eclectic Paradigm of Intenational Production; A Restatement and Some Possible Extentions. Journal of International Bussiness Studies, 19, 1-31.

Dunning, J. H., \& Lundan, S. M. (2008). Multinational Enterprises and the Global Economy (Second Edition). U.S.: Edward Elger Publishing.

Erdilek, A. (2008). Internationalization of Turkish MNEs. Journal of Management Development, 27(7), 744-760.

Erkutlu, H., \& Eryiğit, S. (2001). Uluslararasılaşma Süreci. Gazi Üniversitesi Iktisadi ve Idari Bilimler Fakültesi Dergisi, 3(3), $156-165$.

Hoskisson, R., Eden, L., Lau, C., \& Wright, M. (2000). Strategy in Emerging Economies. Academy of Management Journal, $249-267$.

Johanson, J., \& Vahlne, J.-E. (1977). The Internationalization Process of the Firm--A Model of Knowledge Development and Increasing Foreign Market Commitments. Journal of International Business Studies, 8(1), 23-32.

Kaymakçı, O. (2013). Küresel Ekonomide Çokuluslu Şirketler ve Türkiye'deki Yansımaları. CBÜ Sosyal Bilimler Dergisi, $224-249$.

KHÜ - DEIK - VCC. (2014). Türk Çokuluslu Işletmeleri Araştırması.

Mathews, J. A. (2006). Dragon Multinationals: New Players in the 21st Century Globalization. Asia Pacific Journal of Management, $23,5-27$.

Moon, H.-C., \& Roehl, T. W. (2001). Unconventional Foreign Direct Investment and The Imbalance Theory. International Business Review, $10,197-215$.

Narula, R., \& Dunning, J. H. (2000). Industrial Development, Globalisation and Multinational Enterprises: New Realities for Developing Countries. Oxford Development Studies, 28(2), 1-34.

Ntv. (2007, Aralık 24). Ntv Web sitesi: http://arsiv.ntv.com.tr/news/430263.asp adresinden alınmıştır

Oviatt, B. M., \& McDougall, P. P. (2005). Toward a Theory of International New Ventures. Journal of International Business Studies, 36, 2941.

Özkara, B., Kurt, M., \& Karayormuk, K. (2008). Türkiye'de İşletme Grupları: Eskiler ve Yeniler. Yönetim Araştırmaları Dergisi, 8(1-2), 59-83.

Rasmussen, E. S., \& Madsen, T. K. (2002). The Born Global Concept. 28th ElBA Conference (s. 1-26). Danimarka: Department of Marketing, University of Southern Denmark. 
Sakr, M., \& Jordaan, A. (2016). Emerging Multinational Corporations: Theoretical and Conceptual Framework. Economic Research South Africa.

Seyidoğlu, H. (2003). Uluslararası Iktisat Teori Politika ve Uygulama. İstanbul: Güzem Yayınları.

TCMB. (2016). Uluslararası Yatırım Pozisyonu. Ankara: TCMB.

UNCTAD. (2016). World Investment Report 2016: Annex Table; FDI Outflows By Region and Economy, 1990-2015. UNCTAD.

Wai, H., \& Yeung, C. (2002). Entrepreneurship in International Business: An Institutional Perspective. Asia Pacific Journal of Management, $19,29-61$.

Yadong, L., \& Tung, R. L. (2007). International Expansion of Emerging Market Enterprises: A Springboard Perspective. Journal of International Business Studies, 38(4), 481-498.

Zain, M., \& Ng, S. I. (2006). The Impacts of Network Relationships on SMEs' Internationalization Process. Thunderbird International Business Review, 48(2), 183-205.

Zanfei, A. (2007). The Links between International Production and Innovation: a Double Network Approach. Working Papers Series in Economics, Mathematics and Statistic. İtalya: University of Urbane. 